\title{
Civil Society and Global Governance: The Indirect Participation of Extinction Rebellion in Global Governance on Climate Change
}

\author{
Wahyu Rozzaqi Ginanjar ${ }^{1 *}$, Ahmad Zakky Mubarrok ${ }^{2}$ \\ 1,2Department of International Relations, School of Postgraduate Studies, Universitas \\ Muhammadiyah Yogyakarta, Jl. Brawijaya, Bantul, 55183, Yogyakarta, Indonesia.
}

Received: 2020-02-30; Accepted: 2020-04-27; Published: 2020-04-30

\begin{abstract}
The climate change problem is one of the global challenges faced by global society today. These problems certainly need to be adress in serious manners, especially at the global level. However, for some people, especially at the grassroots, consider global governance related to climate change today is not serious enough to deal with these problems. That is because the nature of the global climate regime is somehow voluntary and non-binding. In this case, civil society can provide the opportunities for the people to contribute to global governance related to climate change. Civil society here can be interpreted as a political space, where association of people can work towards the formation of social and legal rules through nonformal political channels. Extinction Rebellion is one of the civil societies that involves themselves in global discourse related to climate change in international politics arena. This article discusses the form of Extinction Rebellion's involvement in the global climate regime and what dimensions could potentially affected by the movement. This article uses descriptive-qualitative methods with library research data collection techniques. This article found that Extinction Rebellion's involvement in global governance is an indirect involvement with resistance as their mode of participation, which is indicated by the emergence of mass protest in various cities around the world. In addition, Extinction Rebellion initiate discourse on climate change emergencies to illustrate how important climate problems must be handled seriously at the global level.
\end{abstract}

Keywords: Civil Society; Climate change; Extinction Rebellion; Global Governance; Social Movement

How to Cite: Ginanjar, W.R., \& Mubarrok, A.Z. (2020). Civil Society and Global Governance: The Indirect Participation of Extinction Rebellion in Global Governance on Climate Change. Journal of Contemporary Governance and Public Policy, 1(1), 41-52.

Permalink/DOI: https://doi.org/10.46507/jcgpp.v1i1.8 


\section{Introduction}

The Intergovernmental Panel on Climate Change (IPCC), in 2018, warns that humanity has 12 years to take effective action in efforts to prevent environmental disasters. Therefore, there is still enough time to take a firm stand on the issue and implement it with full commitment. To support this, commitment and ambition are needed to radically and rapidly transform global governance, especially in the specs related to high levels of carbon production. In order to follow up on the report from the IPCC, humanity needs to reduce today's high carbon production to zero carbon in less than 12 years (Gunningham, 2019).

The biggest challenge in achieving such transformation is more about politics than technology (Gunningham, 2019). Today, humanity has many low or zero carbon energy sources, for example, wind and solar power plants. Other technologies, such as battery storage, electric cars and a variety of lowcarbon energy sources basically have reached an advanced level and can be improved in the next decade, even faster. However, without political commitment, a low carbon revolution will only be a plan without implementation. In many parts of the world, renewable energy is cheaper than coal but the technology is still struggling to gain market share, largely because of political obstacles (Tramel, 2018). No exception, the strength embedded in the fossil fuel industry, the influence of well-funded and sophisticated climate change disinformation campaigns and disregard, media indifference or bias, and forms of state policies that tend to be oriented towards short-term political and financial markets all hinder long-term oriented political actions related to today's climate crisis.

The problem of low political will at the policy-making level can also be found at the level of global governance. For scientists who have research areas in the climate field, the commitment reached in the Paris Climate Agreement, if successful, is projected to increase the earth's temperature at a point of 3.4 degrees celsius. That, if we refer to the IPCC report, it will be dangerous for the survival of humanity (Gunningham, 2019).

Through the brief description above, it can be said that at the national or international level, there is no policy-making structure that has extra priorities and commitments in order to tackle climate problems, and specifically decarbonization efforts. In this situation, pressures from outside the policy making structure are needed. History shows that such pressure must come from below. In the process, such pressures need to include activist movements at the grassroots level. Keohane and his colleagues argue that pressures from the grassroots level in an industrialized democratic environment are a variable that is more able to influence the direction of environmental-related policies than the decision-making process at international level (Kimball, Haas, Keohane, \& Levy, 1996).

In the last two decades there have been many activist groups that have fought for environmental issues, both at national and international levels. One group that can be said to have a significant impact. One of the social movement groups that emerged recently was The Extinction Rebellion. Extinction Rebellion itself was formed in October 2018. Since then, Extinction Rebellion has been heavily involved in various forms of civil disobedience in several 
countries, especially in London. Since April 2019, Extinction Rebellion has grown in number and has been able to get global public attention. According to Roger Hallam, Extinction Rebellion received wider attention because it had a resonance with the needs and concerns felt by the international public regarding the issue of the climate crisis. Until now, Extinction Rebellion has been present in 45 countries consisting of around 650 local groups (Gunningham, 2017).

This movement (Extinction Rebellion) basically has three main demands that are quite explicit. The first demand is "Tell the Truth!", In which they encourage the national governments of each country to present scientific facts related to today's global climate crisis. The second demand is "Act Now", in which this movement demands the national governments of each country to act and commit to addressing the environmental crisis with a target to reach zero carbon levels by 2025. The third demand is "Beyond Politics" in which they demand for the formation of Citizen Assembly in order to realize decision making based on ecological justice. This, in the perspective of The Extinction Rebellion, is a transformation of the movement from thirty years of global environmental activism (Gunningham, 2019).

Extinction Rebellion has a fairly radical form of protest. One of the most dominant is the method of civil disobedience without violence. Some examples that can be seen are The Extinction Rebellion blockade and disrupt public facilities such as train stations and other public transportation. It is certainly intended to convey messages and influence public discourse about the environment and social activism. The movement is almost similar to the pro-civil liberties movements in the United States in the 1960s. Judging from its historical aspects, movements with protest modes like that tend to be effective in raising public awareness about specific issues.

It was a promising start for the activism and campaign carried out by Extinction Rebellion. With a participatory and inclusive organizational system, this movement is a phenomenon that needs to be studied further, in relation to the participation of civil society in global politics. The emergence of The Extinction Rebellion in our opinion is a phenomenon that reminds the world today, with all developments in political and social aspects at the global level, that it is important to look beyond the nation state in our efforts to find effective and substantial government and policy making systems.

This article will further discuss how The Extinction Rebellion social movement can be involved in global governance. It is intended to find out patterns of involvement that can be carried out by non-state actors, in this case in the form of social movements. In order to get an idea of the involvement of Extinction Rebellion in global governance, we in this article use some literature that can provide a conceptual framework for the mode of participation of Extinction Rebellion in global governance.

\section{Methodology}

In this article, we use literature study as a data collection technique. The data obtained is accessed through books, articles in scientific journals, official documents and internet sources. The data is collected in order to help the writer explain the problem being discussed. The data analysis technique that we 
use in this article is descriptivequalitative analysis technique. The data that we find through various sources are used to describe a phenomenon through interpretation based on a theoretical basis.

\section{Civil Society Involvement in Global Governance}

Referring to the opinion of Antonio Gramsci, the state and civil society cannot be understood as an entirely independent and separate entity (Wise, 2018). Civil society basically includes a set of organizations and institutions, but not limited to it. Civil Society can be interpreted as a "space" of social relations that mediates between individuals and the state (Gready \& Robins, 2017)

Such definitions are often associated with the function and existence of non-governmental organizations (NGOs), but more than that, civil society can be created in various forms. Civil society, in this case, is a totally inhomogeneous structure, it includes various groups, organizations, non-governmental organizations, and social movements that reflect differences, and in many cases, when referring to Gramsci's view, have interests that contradict the state interests (Weiss, 2013)

In the context of global governance, NGOs, social movements, business forums, research institutions, and other civil society associations are involved in global governance in many ways, both directly and indirectly. There are various modes of participation of civil society groups in global governance. The mode of direct participation of civil society groups can take the forms of accreditation, membership of government delegations, policy consultants, positions on official committees and boards, evaluation, and actualization of global regulations themselves. With indirect involvement, civil society groups are trying to form global governance institutions through alternative sectors such as national governments, political parties, and mass media. In other cases, civil society associations involve themselves in global governance by openly opposing them through street demonstrations and various other forms of opposition.

This section will discuss two main points. The first point is related to how the form of participation of civil society groups in global governance and the next point is a discussion related to the extent to which civil society groups can have an impact on global governance.

\section{Form of Participation}

Since

international

organizations have become a real phenomenon in global interaction, civil society can be said to have been directly involved in the global governance process. Some examples that can be found are through the involvement of federations of workers and trade unions involved with the governments of countries in the International Labor Organization since 1920. Increased participation of civil society in the global governance process began to be seen since 1990 . In that period, most of the institutions Large global regulators establish divisions to specifically establish relationships with civil society groups. The World Bank is the largest global regulatory body with such a work pattern, with around 120 specialists from civil society (Weiss, 2013).In addition, most multilateral development banks and various UN agencies in the past two decades have articulated official guidelines for their staff and functionaries in relation to patterns of relations with civil society organizations. 
In some cases, civil society associations have sought indirect involvement in global governance, through third parties. For example, business forums, trade unions, and NGOs usually express their concerns about global governance through member countries, hoping that it will be able to influence the position taken by governments in global institutions (international organizations). In this case, civil society groups involve the foreign ministry for matters relating to the UN, the finance ministry on matters relating to the IMF, the ministry of trade on matters relating to the WTO, and so on. In fact, some state governments actively solicit input from civil society groups before attending major global conferences. Often, countries (especially large countries) are faced with global governance issues not only by civil society associations from their own countries, but also by transnational organizations.

In other cases, civil society groups expressed their aspirations regarding global governance to the legislative branches of government, for example: the French National Assembly, the Japanese Diet, and the United States Congress. Civil society groups in this situation seek to form parliamentary debates on global governance and / or to involve parliamentary committees that examine government policies relating to global governance. In other forms such as in Malawi, civil society associations have sponsored workshops and social activities to increase the capacity of national parliamentarians to deal with global regulatory issues. With regard to the European Union, civil society associations can raise issues with regional parliaments on issues of global governance, especially in the field of trade, where the European Union is a member of the WTO in certain capacities (Weiss \& Wikinson, 2013).

Various non-official channels for indirect civil society involvement in global governance are also available. Outside government, community associations can raise their concerns with global institutions, political parties, mass media, companies, online social networks, and other deliberation spaces such as the World Economic Forum and the World Social Forum. NGOs also sometimes ask celebrities to publish global issues, such as when Greenpeace took young singer Billie Eilish into the Climate Strike campaign in September 2019.

In addition to the direct participation and indirect pressures discussed earlier, civil society actors can engage in global governance with a mechanism of resistance and resistance. These groups tend to reject offers to interact with global institutions. Often, these resistance groups are not invited to interact by parties or official authorities because they are considered to be very disruptive to the process of forming global governance.

Various resistance movements have taken place in the form of taking to the streets to protest what they consider to be dangerous, undemocratic and unjust global governance arrangements. In other resistance tactics, some NGOs initiated a boycott of several large multinational companies, so that this then encouraged the growth of CSR as an official global governance in the production and investment sectors. Street theater, video and demonstrations are other media that can be used by civil society groups in expressing rejection of global governance.

\section{Impact of Civil Society Engagement in Global Governance}


According to Jan Aart Scholte, there are 5 main dimensions that can be used to see the impact resulting from the involvement of civil society in global governance. The 5 dimensions intended are: (1) Dimensions of institutional evolution; (2) Dimension agenda; (3) Decision dimensions; (4) Dimensions of discourse; and (4) Dimensions of social structure (Weiss \& Wikinson, 2013).

First, from the five dimensions of impact mentioned above, civil society can shape the institutional evolution of global regulation. Citizens' associations often advocate the formation, reform and / or dissolution of a global governance body. For example, internationalist groups are urging the formation of the League of Nations and then the United Nations. About 200 NGOs attended the San Francisco Conference which founded the United Nations in 1945, 42 of which were registered as consultants for US government delegations (Weiss \& Wikinson, 2013). Civil society groups also clearly encourage institutional reforms in global governance, such as the formation of the Human Rights Council at the United Nations, the reallocation of quotas at the IMF, and the inclusion of votes for affected communities on the Global Fund to Fight Aids council. So far, the efforts of civil society in the rejection of several international institutions have not been able to become a major factor capable of dissolving a global government institution. However, these movements are at least able to disrupt some formal processions, as happened at the WTO ministry in Seattle. In addition, the emergence of groups from strong radical opposition makes global government bodies more likely to accept institutional reform efforts.
The second dimension, where civil society can impact global governance, is based on the agenda dimension. In other words, citizen activism can influence what issues are considered in the global regulatory process and what needs to be a priority scale (Weiss \& Wikinson, 2013). Civil society associations have been able to push the agenda on a number of global issues that previously received less attention. Some examples are handling AIDS, gun control, corruption, debt, democracy, handling the public rights of people with disabilities, ecological degradation, gender, human rights, humanitarian intervention, indigenous peoples, labor standards, land grabbing, poverty, and others. That would be a little unlikely to be of concern to organizations in global governance without civil society pressure.

The third dimension is the dimension of policy decisions taken in the global governance structure. For example, the WTO's move in 2003 to relax the provisions on intellectual property in essential medicines is a decision made based on the campaigns of several NGOs in this regard. Civil society associations have also been noted to contribute to the ratification of global human rights instruments, initiatives to conduct humanitarian interventions, adjustments to many World Bank projects, and many other policy decisions in global governance.

The fourth dimension is the dimension of discourse that illustrates the ability of civil society to go beyond the ability of individuals to shape discourse in global governance. What is meant by "discourse" here is the concept, language, and framework of overall analysis used in policyrelated discussions. Civil society associations to this day have debated innovation in the core vocabulary of 
global governance by promoting ideas such as "fair trade," "human security," "sustainable development," and "global public good". In general, civil society and its critics are able to make a shift in discourse in global economic governance, which was previously based on the dominant neissiberalism narratives of laissez faire in the late twentieth century, to market rhetoric that emphasized and oriented towards social and environmental aspects in the early twenty-first century (Weiss \& Wikinson, 2013).

The last dimension is the dimension of social structure which illustrates that the impact of civil society is able to reach further by influencing the social structure that underlies global governance itself. The clearest example of this is that civil society associations have promoted changes in overall global governance modes. As we know that in the early eras of the emergence of international organizations, the state was a dominant actor, perhaps even the only actor who had access to global governance arrangements. Civil society pushes the previously statist (state-centered) mode to a more polycentrism mode (where governance occurs through a multiactor network). (Weiss \& Wikinson, 2013) In addition, civil society groups involved in global governance are able to drive changes in the structure of identity in world politics from national-centralism to pluralism. These activism were then able to enlarge the political space for actors who tended to have limited access in global governance in the previous era. The increase in actors and the increasing role of previously insignificant actors will certainly change the patterns and dynamics of interaction between actors in the process of norm formation at the level of global governance.

\section{Extinction Rebellion as Civil Society}

In order to find the correlation between civil society conceptually and whether Extinction Rebellion can be categorized as civil society, in this section we discuss the profile of Extinction Rebellion as a social movement and the extent to which the movement can meet the criteria as a civil society. It aims to reinforce the argument and find social facts related to the discussion in this article.

In general, The Extinction Rebellion is an activist group that has a primary concern with the climate crisis. Started as a project born of a social movement called Rising Up! Extinction Rebellion is projected to be a movement that has a positive influence on the issue of the climate crisis. Rising Up! was established in 2016 to address a number of global problems, one of which is related to climate problems. The main idea in the Rising Up! is a fundamental effort to bring about change in the political and economic fields (Booth, 2019).

Rising Up! aims to achieve this systemic change through civil disobedience, a tactic used by many movements in the past. John Rawls described civil disobedience as 'a public act, nonviolent, and departing from a conscience that is against the law which is usually carried out with a view to bringing about changes in government policy or law'. One of the tactics used in the concept of civil disobedience has been implemented since the Rising Up! into The Extinction Rebellion movement (Booth, 2019).

In the course of that strategy, it leads us to the definition that The Extinction Rebellion is a protest movement based on the principle of nonviolent direct action aimed at forcing governments to overcome the climate and ecological crises faced by 
all the manki. The system that runs in The Extinction Rebellion movement is a movement with a decentralized participatory network.

In April 2019, it declared the 'International Uprising' which created a major disturbance in London, which led to more than 1,000 arrests by the police. Following this, the movement gained more than 40,000 new members and the protest spread to 80 cities and 33 different countries (Skrimshire, 2019).

One of the founding members of Extinction Rebellion, Roger Hallam, wrote that the strategy carried out by Extinction Rebellion was based on three main observations. First, a protest movement needs to be disruptive in order to get public attention. Second, that the activists of this movement must be willing to sacrifice to be responded to and begin a serious dialogue with various parties. Third, that the movement must be based on respect in the process of building public opinion regarding the issue that being advocated. This has direct implications for the tactics used by Extinction Rebellion throughout the world, which focuses on large groups of people committing lawlessness, in the context of disturbing public convenience, in a truly nonviolent manner for an ongoing period. This then creates economic disruption, which is designed to shake the political system, and civil disturbances. All of these things are designed in order to convey a message and raise awareness of the importance of starting a serious dialogue on climate crisis at the public level (Hallam, 2019).

The message to be delivered by Extinction Rebellion is quite clear. That we are facing a climate crisis and an ecological emergency that presents an existential threat to the continued existence of humanity. This movement specifically highlights the 2018 Intergovernmental Panel on Climate Change (IPCC) report which focuses on the need to keep global warming stable below 1.5 degrees Celsius. This confirms the scientific consensus that the current change in the global climate is a direct implication of human activity which also underlines the magnitude of the consequences of the changes that occur today. Direct ecological impacts can be seen in sea level rise, extreme weather events, drought, flooding, loss of biodiversity, food insecurity, sea acidification, reduced water supply and its negative effects on human health and even lead to war. The report stresses that the human population that will be most affected and most severely affected by climate change are vulnerable groups such as indigenous peoples and those who rely on agricultural or coastal livelihoods. It is generally accepted that we have seen an increase in extreme weather events such as forest fires, heat waves, hurricanes and cyclones, floods, and drought. Based on this, the position taken by The Extinction Rebellion that current climate change can be categorized as a global climate emergency has a strong reason, both in the moral and scientific dimensions (Hallam, 2019).

Based on the brief explanation above, if we refer to the concept of civil society as a political space that connects people with the state, The Extinction Rebellion can be interpreted as a civil society group, in the form of a social movement. Protest and mass action is a strategy carried out by Extinction Rebellion. Based on the strategy carried out by Extinction Rebellion in voicing its demands, it can be seen that the national government is the target of this movement. Referring to this, we can say that the mode of involvement of The Extinction Rebellion in the 
issue of global climate problems is indirect involvement. That is because the mode of participation implemented by The Extinction Rebellion here is not in a formal form. In the sense that The Extinction Rebellion is not directly involved in global forums related to climate issues, but rather informal participation in the form of protests and mass actions. The indirect participation of The Extinction Rebellion here is in the form of resistance.

In assessing the dimensions of potential impacts to be pursued by campaigns and movements initiated by The Extinction Rebellion, we need to look at what dimensions are contained in the points of The Extinction Rebellion's own demands. The next section will discuss the dimensions of the impact that The Extinction Rebellion wants to pursue in its relationship with global governance on environment and climate change.

\section{The Dimension of Involvement Pursued By Extinction Rebellion In Global Governance.}

The Extinction Rebellion has three demands for the government. The first is that the government 'Tell the Truth' and declares climate emergency. Emergencies are situations where our normal ways of managing society and the economy cannot adequately handle the risks we face. Therefore, this implies a change in what we do, commensurate with the scale and urgency of risk. The emergency situation demanded by The Extinction Rebellion here has practical and political dimensions. Declaring a state of emergency in this case will result in the development of a plan, supported by strong leadership, which communicates, coordinates, and disseminates practical and financial capacity to protect people from threats, including the most vulnerable. In most emergencies, only countries have the authority and capacity to act this way. Society depends on the state to do it .

For the context, today, the levels of carbon dioxide ( $\mathrm{CO} 2$ ) and methane have reached historic highs for the human era. This represents the condition of our current response to risk. There has not been a reduction in total emissions, which creates risks, some 30 years after it was discovered that climate change is a threat, despite urgent global acceptance (Gilding, 2019). We should not confuse high awareness, global agreements and debate with any effective action to alleviate these threats. Scientists warn that even if all Paris emission commitments are met, temperatures will surpass $1.5^{\circ} \mathrm{C}$ warming (the target was agreed in Paris), and then increase 3 to $5^{\circ} \mathrm{C}$ by 2100 (Gilding, 2019).

In this first point of demand, we see that The Extinction Rebellion pursues the dimension of influence to form a more representative discourse in describing the reality and scientific facts related to today's global climate situation. The "Climate Emergency" diction here is a concept that The Extinction Rebellion tries to distribute, rather than mere "Climate Change", in order to influence public discourse on climate issues. The concept of "climate emergency" itself is supported by comprehensive scientific data so that it is very possible to get legitimacy from people which in turn will affect people's perceptions in interpreting climate problems (Gilding, 2019).

The second demand, 'Act Now'. In this demand, The Extinction Rebellion demands that the National Government enact legally binding policies to reduce carbon emissions to zero net by 2025 and take further action to eliminate excess greenhouse 
gases in the atmosphere. It must work together internationally so that the global economy runs no more than half the planet's resources per year. In other words, at the point of this demand, Extinction Rebellion is demanding that national governments around the world economize frugally and limit production with the aim of balancing carbon production with today's climate situation (The Extinction Rebellion, 2019).

In this second point of demand, we see that The Extinction Rebellion pursues an influence dimension in the form of an agenda. The Extinction Rebellion seeks to encourage national governments and global regulatory bodies to make the problem of the climate crisis a top priority that must be resolved. This can be interpreted as a follow-up from the first demand points related to climate emergency which requires major efforts, especially in matters of political decisions, resource mobilization, and priority scale.

The third demand, 'Beyond Politics', is the government creating a citizen assembly to manage the changes that need to be made. This model of democratic governance has been used successfully in Ireland, among other countries, to deal with significant and / or divisive issues such as abortion and gay marriage. The Extinction Rebellion shows that this solution will produce a form of government capable of making the long-term radical policy decisions needed to effectively deal with climate and ecological emergencies (The Extinction Rebellion, 2019).

Citizen Assemblies are a type of deliberative democracy, a mechanism where ordinary people make political decisions. Members of Citizen Assembly are randomly chosen from the population. This procedure is close to how a jury is chosen in the UK and a number of other countries' legal system. Furthermore, the organizers of assemblies use demographic quotas to ensure that they are inclusive in terms of a number of variables, such as gender, age, ethno-cultural origin, level of education, sexual orientation, disability and geography. Once participants have been chosen, there are four main phases to the process: listening, studying, deliberating, and decision making (The Extinction Rebellion, 2019).

Public engagement serves as a counterpoise to a political framework that prioritizes short-term electoral advantages over current and future generations' long-term needs. Deliberative mechanisms, backed up by bias-free protections, leads to more diverse and educated voices in political discourse than in a solely elected body like the House of Commons. Additionally, assembly members are not chosen to represent political parties and are free to make decisions solely based on their own informed viewpoints, values and a sense of what policies would be for the common good (Hallam, 2019).

In this demand point, we see that The Extinction Rebellion pursues impacts in global governance in the dimension of institutional evolution. The institutional evolution here can be seen from The Extinction Rebellion's efforts to drive radical change, especially in the context of decision making, related to the problem of the climate crisis. The Extinction Rebellion encourages institutional evolution in climaterelated global governance from previously limited to the political elite, rather to citizen assembly. What this means is that The Extinction Rebellion is trying to change the traditional policy-making process to the participation of the public and 
experts in formulating policies related to the climate crisis.

\section{Conclusion}

It can be concluded that The Extinction Rebellion as a civil society has a form of indirect involvement, because here the mode of participation carried out by The Extinction Rebellion is in the form of mass protest and demonstration. In this regard, The Extinction Rebellion has involvement outside the formal structure of global governance. The dimensions pursued by The Extinction Rebellion are: (1) Dimensions of discourse; (2) Agenda Dimensions; and (3) Dimensions of institutional evolution.

The dimension of the discourse pursued by The Extinction Rebellion is in the form of a new concept that illustrates the scientific facts of today's situation related to the climate crisis. The concept of "climate emergency" offered by The Extinction Rebellion is an effort in shaping public discourse, which has the potential to influence public perceptions in interpreting today's climate crisis. The growing discourse on climate emergency can also influence the discourse on the climate crisis at the level of policy makers, so that it can change the perception of the global community regarding today's climate crisis.

The second dimension is the dimension of the agenda, where The Extinction Rebellion tries to push climate problems as a top priority that needs to be resolved at the national level to global governance. This is a follow-up to the definition of climate-related emergencies in the first case.

The third dimension is the institutional evolution where The Extinction Rebellion encourages direct public involvement in decision making related to climate issues at national and global levels. This is an effort to revolutionize traditional policy making patterns that focus only on formal political actors, both at the national and global levels. The involvement of the public and experts here is a form of deliberative mechanism which can then provide alternative policies that are not affected by electoral politics.

\section{Acknowledgments}

We express our sincere thanks to Lecturer and Student of Department of International Relations, School of Postgraduate Studies, Universitas Muhammadiyah Yogyakarta for valuable help during this manuscript preparation work.

\section{References}

Booth, E. (2019). Extinction rebellion: Social work, climate change and solidarity. Critical and Radical Social Work, 7(2), 257261.

https://doi.org/10.1332/2049 86019X15623302985296

Gilding, P. (2019). Climate Emergency Defined (1st ed.). Melbourne: Breakthrough - National Centre for Climate Restoration.

Gready, P., \& Robins, S. (2017). Rethinking civil society and transitional justice: lessons from social movements and 'new' civil society. International Journal of Human Rights, 21(7), 956-975. https://doi.org/10.1080/1364 2987.2017.1313237

Gunningham, N. (2017). Building Norms from the Grassroots Up: Divestment, Expressive Politics, and Climate Change. Law and Policy, 39(4), 372392. https://doi.org/10.1111/lapo. 12083

Gunningham, N. (2019). Averting Climate Catastrophe: Environmental Activism, 
Extinction Rebellion and coalitions of Influence. King's Law Journal, 30(2), 194-202. https://doi.org/10.1080/0961 5768.2019.1645424

Hallam, R. (2019). Common Sense to the 21st Century. Retrieved from

https://www.rogerhallam.com /wpcontent/uploads/2019/08/Co mmon-Sense-for-the-21stCentury_by-Roger-HallamDownload-version.pdf

Kimball, L. A., Haas, P. M., Keohane, R. O., \& Levy, M. A. (1996). Institutions for the Earth. Sources of Effective International Environmental Protection. The American Journal of International Law, 90(4), 701. https://doi.org/10.2307/2204 002

Skrimshire, S. (2019). Activism for End Times: Millenarian Belief in an Age of Climate
Emergency Activism for End Times : Millenarian Belief in an Age of Climate Emergency. Political Theology, 20(6), 518536.

https://doi.org/10.1080/1462 317X.2019.1637993

The Extinction Rebellion. (2019). The Extinction Rebellion Guide To Citizens' Assemblies. Extinction Rebellion, 1, 1-28.

Tramel, S. (2018). Convergence as political strategy: social justice movements, natural resources and climate change. Third World Quarterly, 39(7), 12901307.

https://doi.org/10.1080/0143 6597.2018.1460196

Weiss, T. G. (2013). International Organization and Global Governance. In T. G. Weiss \& R. Wilkinson (Eds.), International Organization and Global Governance (1st ed.). https://doi.org/10.4324/9780 203795972

(C) 2020 by Autors. Submitted for possible open access publication under the terms and conditions of the Creative Commons Attribution (CC BY SA) license (https://creativecommons.org/licenses/by-sa/3.0/). 